\title{
Analysis and comment
}

\section{Commercial bias in medical journals \\ Commercial influence and the content of medical journals}

\author{
Joel Lexchin, Donald W Light
}

How confident should we be in the objectivity of medical journals? Do commercial biases play a part in determining what appears in print?

School of Health Policy and

Management, York

University, Toronto,

ON, Canada

Joel Lexchin

associate professor

University of

Medicine and

Dentistry of New

Jersey, Stratford, NJ

USA

Donald W Light

professor

Correspondence to:

J Lexchin, 121

Walmer Road,

Toronto, ON,

Canada M5R 2X8

jlexchin@yorku.ca

BMJ 2006;332:1444-7
Authors of articles in medical journals may be affected by commercial bias. Whether this same concern applies to the editors and owners of journals has rarely been critically examined. ${ }^{12}$ Our article explores the reasons for concern. We use information in the literature on three important questions. Do financial conflicts of interest affect decisions made by journal editors? Do journals have policies on authors' conflicts of interest, and how well do editors enforce those policies? Do financial considerations affect the content of medical journals? We end with a proposal for future research that would help to advance this debate.

\section{Sources of bias}

Government organisations and societies of health professionals can also influence journal content. A former editor of JAMA was fired by the American Medical Association because of political sensitivity over an article on oral sex that he published at the time of President Clinton's impeachment. ${ }^{3}$ An article in $C M A J$ on the information requested by pharmacists before dispensing postcoital contraception was changed after complaints by the Canadian Pharmacists Association about whether the research was ethical. ${ }^{4}$ However, we think that the greatest potential for bias comes from commercial influences, hence the direction of our article.

\section{Conflicts of interest}

Because journal editors have a great deal of control over original scientific articles, commentaries, and editorials, any commercial bias due to their own conflict of interest would affect the content of their journals. ${ }^{5}$ Only one systematic study has examined editors' policies on conflict of interest (financial and non-financial). Nine of 30 peer reviewed general and internal medical journals, including the top four by impact factor (a measure of frequency of citation), had an explicit policy for dealing with editors' financial conflicts of interest. Only eight of the remaining journals intended to declare such conflicts in the next couple of years.
Reasons for non-disclosure were that disclosure is unnecessary, that editors do not have conflicts, and that the question had never been raised. ${ }^{6} 7$

An article about the benefits of escitalopram (Lexapro) over citalopram (Celexa) provides an example of apparent editorial conflict of interest. The article, by Jack M Gorman, was published in a special supplement of CNS Spectrums, a neuropsychiatric journal that he edits. The article, which was published at a time when the patent for citalopram was expiring, concluded that escitalopram significantly improved primary endpoint efficacy scores in trial subjects "much sooner" than did citalopram and was "welltolerated." Dr Gorman was a paid consultant to Forest (which marketed both drugs), and Forest paid Medworks Media, the publisher of CNS Spectrums, to print the article, ${ }^{8}$ although Dr Gorman stated at the time the article was published that he was not paid personally to write it." A comparison of these two drugs published in Medical Letter, an independent drug bulletin with no advertising, found no difference between the two drugs. ${ }^{9}$

Editors might not pursue aggressive conflict of interest policies in their journals and may fail to enforce existing policies. A 1999-2000 survey of the 24 basic science journals and 24 clinical journals with the highest immediacy index rankings (how fast the average article in a particular journal will be discovered and cited) found that only 20 of the 47 that responded reported having policies for the disclosure of conflict of interest. ${ }^{10}$ Definitions of conflict of interest varied greatly, and disclosure of certain conflicts could be avoided; for instance, 10 journals required disclosure of income and equity interests, but only seven asked for patent ownership to be reported, and only one required appearances of conflicts to be reported.

Despite recent improvements in five leading medical journals in the proportion of articles declaring conflict of interest, 8\% (13 of 163) original articles published from December 2003 to February 2004 in four major journals failed to declare conflicts. ${ }^{112}$ Narrowly defining conflicts and not vigorously enforcing journal policies may result in editorial decisions that lead to the publication of articles with a commercial bias. 
Revenue from advertisements in six major US medical associations and journals

\begin{tabular}{|c|c|c|c|c|}
\hline \multirow[b]{2}{*}{ Journal } & \multirow[b]{2}{*}{ Organisation } & \multicolumn{3}{|c|}{ Revenue } \\
\hline & & Annual (\$m) & $\%$ of total & $\begin{array}{c}\% \text { of membership } \\
\text { fees and } \\
\text { assessments }\end{array}$ \\
\hline Journal of American College of Cardiology & American College of Cardiology & 4.7 & 13.8 & 93.0 \\
\hline Annals of Internal Medicine & American College of Physicians & 6.0 & 12.9 & 133.9 \\
\hline$\overline{J A M A}$ & American Medical Association & 18.6 & 10.4 & 26.2 \\
\hline $\begin{array}{l}\text { American Journal of Respiratory and Critical } \\
\text { Care Medicine }\end{array}$ & American Thoracic Society & 0.7 & 2.1 & 17.1 \\
\hline Clinical Infectious Diseases & Infectious Disease Society of America & 0.7 & 31.3 & 125.4 \\
\hline New England Journal of Medicine & Massachusetts Medical Society & 14.3 & 21.3 & 792.7 \\
\hline
\end{tabular}

\section{Commercial supplements}

Journal supplements are a good example of how financial considerations can influence the editorial content of medical journals. Supplements are mostly paid for by drug companies and usually contain articles about a single drug marketed by the company. These articles are usually based on papers presented at symposiums sponsored by drug companies. Because the publisher is paid according to the number of papers in each supplement, lax standards for these articles will generate more revenue than stricter standards. ${ }^{1}$ As a result, the scientific quality of most papers in supplements is inferior to those published in the main journal. ${ }^{13}$

\section{Marketing reprints}

Most high profile, peer reviewed journals produce press releases for newsworthy articles to generate media attention. Greater media attention leads to more subscriptions, more advertising, and the sale of article reprints, all of which result in greater revenue. Journals aggressively advertise reprint sales, as shown by an advertisement on the web page of the $B M J$ : "Reprints are invaluable for direct marketing, exhibitions/seminars and sales support campaigns and for mailing new product information to doctors (and for distribution) to conference delegates and visitors at exhibitions." ${ }^{14}$ Companies may spend up to $\$ 1$ million ( $£ 0.53 \mathrm{~m} ; € 0.77 \mathrm{~m}$ ) on purchasing reprints, and the former editor of the $B M J$, Richard Smith, thinks that this situation can create a conflict for journal editors: "Publish a trial that will bring US\$100 000 of profit or meet the end-of-year budget by firing an editor." 12

\section{Revenue from journal advertising}

One study looked at the revenue from journal advertising as a proportion of the total income of six non-profit making doctors' organisations that owned journals. ${ }^{15}$ Five organisations obtained more than $10 \%$ of their gross income from advertising in their journals, and in four cases as much (or nearly as much) money was generated from advertising as from members' fees and "other assessments" (table). The authors concluded, "potential financial conflicts of interest arising from pharmaceutical advertisements in medical journals may be substantial." Of note, journals do not routinely report details of their sources of revenue, such as subscriptions, journal advertisements, and sales of reprints.

Companies may refuse to advertise in journals that publish articles that are critical of the drugs industry. In 1992, the Annals of Internal Medicine published an article that critically examined the scientific accuracy of advertisements for drugs in 10 leading medical journals. ${ }^{16}$ Reviewers (doctors and pharmacists) judged that $34 \%$ should have been revised before publication, and 28\% should not have been published. After publication of this article, the decrease in drug advertisements in the Annals was greater than in four leading general medical journals (figure). ${ }^{17}$ The journal lost an estimated \$1-1.5 million in advertising revenue by publishing the study. ${ }^{18}$ The editor said, "The episode revealed the true colours of the pharmaceutical industry, which was willing to flex its considerable muscles when it felt its interests were threatened." ${ }^{19}$ The potential effects of articles on advertising revenue may consciously or subconsciously affect editors' decisions about publication or may influence which authors are asked to contribute.

In some journals, marketing considerations seem to be more important than editorial decisions. Despite three good peer reviews, the editor of a leading nephrology journal, Transplantation and Dialysis, rejected an editorial questioning the value of epoetin in end stage renal disease. The editor admitted to the author of the editorial, "I have been over-ruled by our marketing

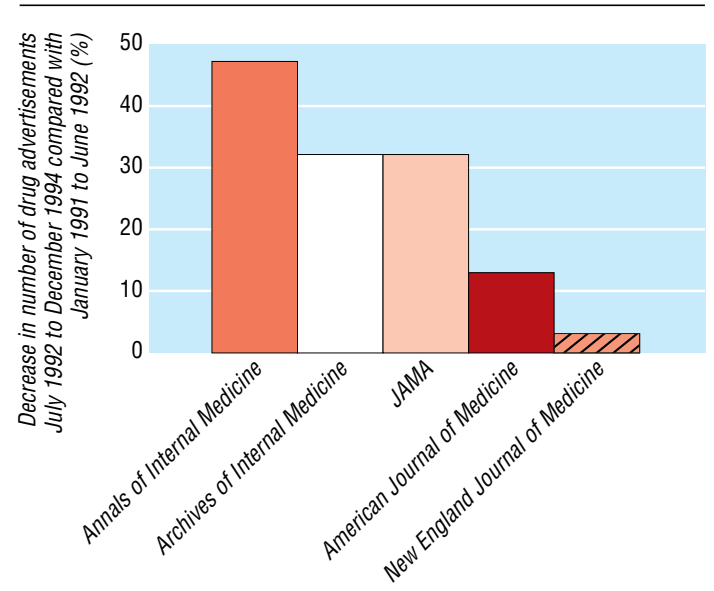

Changes in advertising revenue for five leading medical journals after Annals of Internal Medicine published an article that criticised advertisements for drugs in medical journals 
department with regard to publishing your editorial ... the publication of your editorial would, in fact, not be accepted in some quarters... and apparently went beyond what our marketing department was willing to accommodate., ${ }^{20}$

Without drug advertising, journals are economically vulnerable. Only two general medical journals have stopped advertising drugs, and one of these had to stop publication a little more than three years after doing so.

\section{Recommendations for action}

Commercial bias in medical journals owing to financial pressure or editors' conflicts of interest would represent a fundamental threat to the credibility of journals and to science as a whole. The studies cited here provide evidence for concern about commercial influence. In this light, we recommend some easily implemented measures to help alleviate these concerns.

- Journals should publish detailed information about their sources of income, including the amount they get from the sale of reprints, supplements, and advertising; - At a minimum, editors should follow the recommendations of the Committee on Publication Ethics (COPE), a forum for editors of peer reviewed journals formed to discuss issues related to the integrity of the scientific record. Editors should disclose their own relevant conflicts of interest to readers and consider disclosing those of their editorial teams, editorial boards, managers, and owners;

- Journals should consider not allowing editors to have any direct financial ties (for example, stock ownership, speaker's fees, advisory board participation) to any healthcare business that advertises in the journal that they edit;

- The International Committee of Medical Journal Editors (ICMJE) or a similar organisation such as the World Association of Medical Editors should design a template for journals that would record the wide range of financial interactions that authors might have with commercial entities and journals should publish these authors' statements in full, either in print or electronically, in conjunction with the articles;

- Editors should consider publishing earlier versions of manuscripts on the internet together with reviewers' and editors' comments, so that readers can see how the tone and content of articles was changed. This information could help detect the origin of any bias.

All journals should be strongly encouraged to adopt these recommendations so that those that cooperate will not suffer financially compared with those that do not.

In addition, the influence of commercial interests on medical journals should be investigated systematically. A respected and independent body, such as the Institute of Medicine in the United States, should study the past five years' contents of a selection of leading medical journals and look for bias in articles that deal with specific drugs and pharmaceutical policy in general. Such a study would allow comparisons between journals and over time to detect trends in publications. The results should be reported to the profession and the public.

\section{Summary points}

Most general and clinical medical journals do not have policies on conflicts of interest for their editors

Articles published in sponsored journal supplements bring in substantial revenue for the publishers of journals

Non-profit making doctors' organisations may receive more revenue from advertising in journals than from members' fees

Journals do not seem to be able to survive without advertising

Articles in medical journals that criticise the drug industry can result in substantial loss of advertising revenue

Systematic research is needed to determine whether commercial interests influence the decisions of journal editors and owners

Publishing medical journals is not a charitable venture, even when the owners are non-profit making medical societies. Considerable financial resources are needed to publish high quality journals, and owners and editors are vulnerable to economic pressures that may threaten the intellectual integrity of their journals. The medical community should objectively and dispassionately investigate whether this concern is a reality.

Contributors and sources: JL has been conducting research into pharmaceutical policy for more than 20 years and has authored or coauthored more than 60 peer reviewed articles in this area, as well as serving as a consultant to various nationa governments and the World Health Organization on pharmaceutical matters. DL is a professor of comparative healthcare policy, a contributor to the WHO observatory volume on European pharmaceutical policy, and a member of the taskforce for the Gates Foundation on how best to make vaccines for global diseases economically viable. DL had the initial idea for the article. JL did most of the literature searching and retrieval and wrote the various drafts. DL made intellectual contributions to the analysis of the literature and helped with revisions. Neither of the authors received any financial rewards for writing this article. JL is guarantor.

Competing interests: None declared.

1 Smith R. Medical journals and pharmaceutical companies: uneasy bedfellows. BMJ 2003;326:1202-5.

Smith R. Medical journals are an extension of the marketing arm of pharmaceutical companies. PLoS Med 2005;2:e138.

Hoey JCC, Elmslie T, Flegel KM, Joseph KS, Palepu A, Todkill AM. Science, sex and semantics: the firing of George Lundberg. CMAJ 1999;160:507-8.

4 Kassirer JP, Davidoff F, O'Hara K, Redelmeier DA. Editorial autonomy of CMAJ. CMAJ 2006; 174:945-50.

5 Wilkes MS, Kravitz RL. Policies, practices, and attitudes of North American medical journal editors.J Gen Intern Med 1995;10:443-50.

Haivas I, Schroter S, Waechter F, Smith R. Editors' declaration of their own conflict of interest. CMAJ 2004;171:475-6.

7 Schroter S. A survey of editors' conflicts of interest. In: White C, ed. The COPE report 2003: annual report of the committee on publication ethics. London: BMJ Books, 2004:24-31.

8 Petersen M. Madison Ave has growing role in the business of drug research. New York Times 2002 November 22; sect A: 1

Escitalopram (Lexapro) for depression. Medical Letter 2009:44:83-4.

10 Van McCrary S, An

Wray NP, et al. A national survey of policies on disclosure of conflicts of Wray NP, et al. A national survey of policies on disclosure of cont
interest in biomedical research. N EnglJ Med 2000;343:1621-6. 
11 Hussain A, Smith R. Declaring financial competing interests: survey of five general medical journals. BMJ 2001;323:263-4.

12 Goozner M. Unrevealed: non-disclosure of conflicts of interest in four leading medical and scientific journals. Washington DC, US: Centre for Science in the Public Interest, 2004. www.cspinet.org/new/pdf/unrevealed_final.pdf (accessed 15 May 2006).

13 Cho M, Bero L. The quality of drug studies published in symposium proceedings. Ann Intern Med 1996;124:485-9.

14 Ray J. Judging the judges: the role of journal editors. $Q J$ Med 2002;95:769-74.

15 Glassman PA, Hunter-Hayes J, Nakamura T. Pharmaceutical advertising revenue and physician organizations: how much is too much? West J Med $1999 ; 171: 234-8$.
16 Wilkes MS, Doblin BH, Shapiro MF. Pharmaceutical advertisements in leading medical journals: experts' assessments. Ann Intern Med 1992:116:912-9. journals: experts assessments. Ann Intern Med

17 Landefeld C, Chren M, Siddique R. A 4-year study of the volume of drug advertisements in leading medical journals. J Gen Intern Med 1995;10(suppl):111.

18 Altman LK. Inside medical journals, a rising quest for profits. New York Times 1999 August 24; sect F: 7.

19 Fletcher RH. Adverts in medical journals: caveat lector. Lancet 2003;361:10.

20 Dyer O. Journal rejects article after objections from marketing department. BMJ 2004:328:244.

(Accepted 28 April 2006)

\title{
First person
}

\section{The price of independence}

\author{
Joe Collier
}

Career pressure and a focus on payment by results are making the critical and impartial thinker an endangered species. Society must take steps to protect this invaluable resource

My professional life has been dominated by a drive to ensure that every opinion or piece of advice I give is independent and seen as such. Independence first became an issue for me in 1969 when I edited my first article for Drug and Therapeutics Bulletin. ${ }^{1}$ The then editor, Andrew Herxheimer, made my responsibilities clear: I was to scrutinise all the relevant published data, read and note all of the comments made by article reviewers, and use all this information to prepare the article for publication, ensuring clarity, reliability, and impartiality. The published article must reflect the scientific knowledge available and distinguish what was known about the product from what was derived from conjecture, bias, or the uncritical position of the establishment. Moreover, there would be no place for my own (preconceived) biases. Readers were to be given information they could trust and be confident that the advice given had no hidden agenda no ulterior motive.

Four decades on, and I am still discovering the full implications of these ideals. Their meaning became more pertinent when I was appointed the bulletin's deputy editor in 1972, then its editor in 1992, and a year later when it coined the strapline, "The independent review for doctors." Perhaps, more importantly, the ideals have taken on new dimensions as they have shaped my career as teacher, researcher, physician, administrator, writer, broadcaster, and adviser.

\section{What is independence and does it matter?}

In the context of this article, independence relates to intellectual function, the way our minds process information to make decisions; ultimately, it is the way we make up our minds and, as advisers, give our opinions.

What has emerged over the years is that my views have needed to be much more than independent. To be of real value, they have needed to be delivered in a way that the message was clear, pertinent, honest, and unambiguous. Advice that can be misinterpreted or leaves room for misunderstanding is often unusable and may be dangerous. In my experience, people who

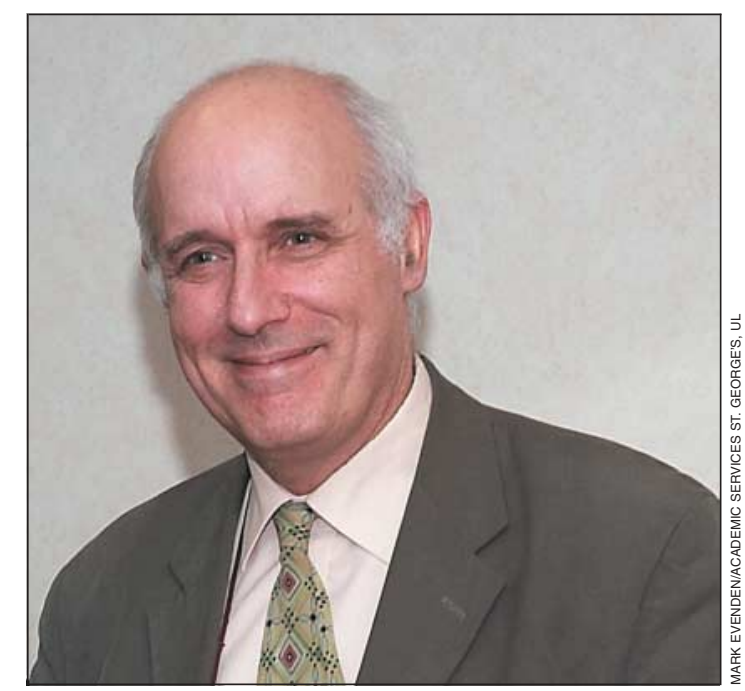

St George's Hospital and Medical School, London SW17 0RE Joe Collier professor of medicines policy jcollier@sgul.ac.uk BMJ 2006;332:1447-9 have conflicts of interest often find giving clear advice (or opinions) particularly difficult.

Advice also needs to target the recipients' needs and respond to their concern or question, whether the recipient is a patient, a government minister, a committee, or one of millions of people listening to a broadcast or reading an article. How advice or opinion is couched and delivered will depend on the particular circumstances. Sometimes it will be signalled simply by the act of raising your hand to vote at a meeting, sometimes be spoken as part of the rapid deliberations of the busy committee, sometimes be more measured (as when presenting a report), and sometimes argued in detail (as in an article in a medical journal). Whatever the method, the responsibilities of the independent adviser remain the same.

\section{Sources of bias}

So what influences might undermine impartiality? In advice relating to medicines, drug companies are 